\title{
Thermal Treatment of Carbidostals TiC - I2XI8H10T
}

\author{
Leonid M. Savinykh ${ }^{1, a^{*}}$, Stanislav Y. Pomyalov ${ }^{1, b}$, Tatyana A. Dudorova ${ }^{1, b}$ and \\ Tamara A. Verzhbalovich ${ }^{1, b}$
}

${ }^{1}$ Kurgan State University, Kurgan region, Kurgan, Russia, 640020

asavinih_LM.polytech@kgsu.ru, bpomialov_45@mail.ru, cdudorovatan@yandex.ru, dZhuksks@list.ru

Keywords: Carbidostal, Heat Treatment, Impregnation, Annealing, Quenching, Tempering, Sintering, Strength, Austenite, Ferrite, Hardness

\begin{abstract}
An important task of thermal treatment of carbidostals having different composition of titanium carbide and steel I2XI8H10T is the possibility of improving their strength properties during operation under abrasive wear conditions. This question is new and little studied.
\end{abstract}

\section{Introduction}

Carbidostals obtained by impregnating the carbide carcass with a steel melt generally have a higher density and toughness than those obtained by conventional pressing and sintering methods. This is achieved by obtaining a structure with isolated fine inclusions in the steel matrix, a significant technological advantage of the process of producing carbidostal by impregnation is the fact that when forming a carbide frame, small pressures are used to compress titanium carbide powders, this makes it possible to manufacture articles of complex shape.

Carbidostals, like alloyed steels, are subjected to all types of heat treatment (annealing, quenching and tempering), the structure of the carbidostals depends significantly on their heat treatment, which can also cause diffusion redistribution of components between the refractory phase and the steel matrix. The physical and mechanical properties may depend on the method of producing the carbidostals.

Therefore, the study of heat treatment modes for this carbidostal chemical composition was a pressing issue. The ability of carbidostals to anneal allows them to reduce their hardness so much that they can be machined and the possibility of using one or another machining after annealing is determined by the ratio of carbide and steel components, the greater the content of refractory phase, the higher the hardness of the carbidostal and the more difficult its treatment in annealed state. The annealing modes of the carbidostal are determined by the steel class used as a binder and generally correspond to the annealing modes of these steels.

\section{Theoretical provisions}

All types of heat treatment (annealing, quenching and tempering) were carried out in a resistance furnace in an argon atmosphere. The prototypes were $16 \times 16 \times 10 \mathrm{~mm}$ in size.

The annealing operation was carried out to homogenize, relieve internal stresses, and obtain a more uniform structure. Annealing mode is selected according to literature data [1, 2]. Heating was carried out to $1140 \mathrm{~K}$, holding - 1 hour, cooling - with the furnace to $990 \mathrm{~K}$, holding at this temperature $\mathrm{b}$ hour, subsequent cooling with the furnace. Microstructures of carbidostal TiC $45 \%$ I2XI8H10T after impregnation and annealing are given in Figure 1. As can be seen from the above micrographs, after annealing there were no noticeable changes in the structure of the carbidostal on the non-etched grinding. Quantitative analysis of structural constituents (Table 1) showed a tendency to increase carbide grains after annealing. The ratio of carbide to metal phases 
after annealing also remained substantially unchanged (Table 2). However, the composition of the metal matrix appears to have changed as the austenite became ferrite after annealing. If before annealing, according to the X-ray structural analysis, the austenite lattice parameter $\mathrm{a}=3,602 \mathrm{~A}$, then after annealing, doped ferrite was fixed with the lattice parameter $\mathrm{a}=2,864 \mathrm{~A}$. Magnetic weighing of the samples confirmed the data of X-ray structural analysis: after impregnation, the carbidostal was not attracted by the magnet, after annealing, it was attracted well. Results of magnetic weighing before annealing $-4,4 \mathrm{~g}$, after $-404,5 \mathrm{~g}$.

The conversion of $\gamma-\alpha$ during annealing can be explained by the fact that during annealing, part of the titanium and chromium carbides leave the solid solution, carrying carbon with them. attracted, after annealing - attracted well. Results of magnetic weighing before annealing $-4,4 \mathrm{~g}$, after $-404,5 \mathrm{~g}$.

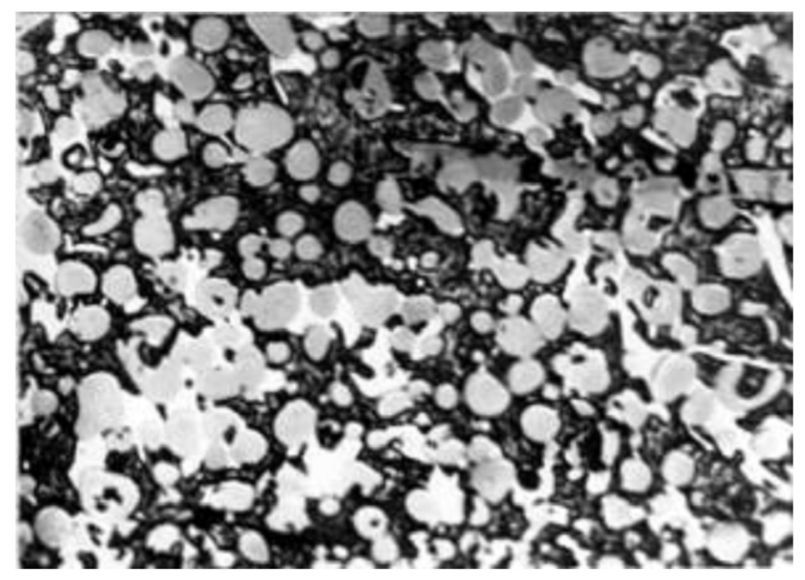

a

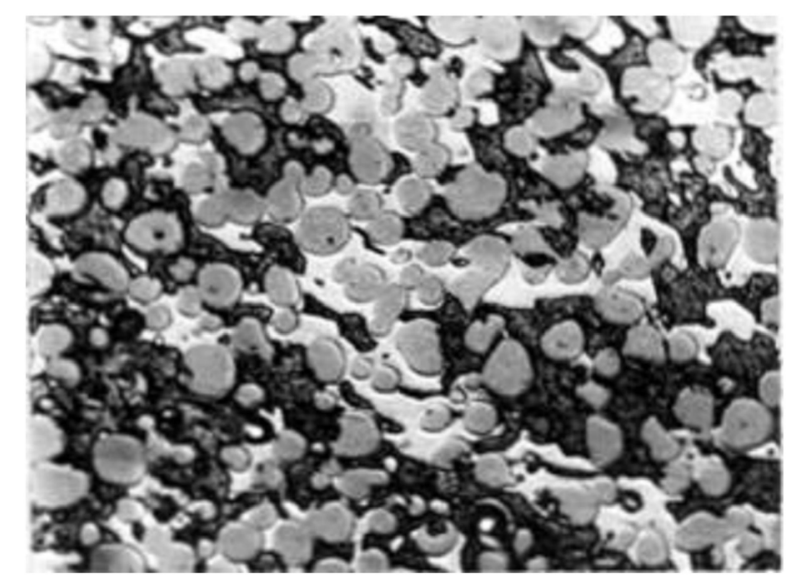

b

Fig. 1. The microstructure of the carbidostat TiC - 45\% X18H10T after impregnation (a) and annealing (b), $x 800$

A decrease in the carbon content of stainless steel and possibly an increase in the titanium content which is transferred from the carbide of the non-stoichiometric composition leads to a narrowing of the $\gamma$-region and an expansion of the $\alpha$-iron region. This is the reason for the conversion of austenite to ferrite during annealing. The separation of titanium carbides and possibly chromium from the solid solution during annealing is indirectly confirmed by some decrease in the microhardness of the metal bond (Table 1).

It should be noted that with sufficiently slow cooling of the samples after impregnation, a ferrite structure of the steel matrix is also obtained. Since the ferrite structure reduces the wear resistance of the carbidostal, it is necessary to apply heat treatment after impregnation to form the austenitic structure of the steel matrix. As experiments have shown (Table 2), such heat treatment is quenching followed by tempering. On the other hand, the presence of ferrite, that is, the possibility of carbidostal being magnetic, is a positive point. In some cases, the article must be subjected to grinding treatment. Consequently, the article will be held firmly on the magnetic plate of the grinding machine.

The hardening modes of the carbidostals are also determined by the composition of the steel bond. Carbidostals are characterized by no changes in linear dimensions after quenching, in order to carry out the following task, wrapping the hardened parts in stainless steel foil or heating neutral.

The most complete dissolution of carbides in austenite is observed when heating the carbidostal under quenching to a temperature of $1270 \mathrm{~K}$ and holding at this temperature for 1 hour [3]. 
Magnetic weighing after quenching in this mode detected the minimum weight of the a-phase, and the lattice parameters of the alloyed austenite after quenching - $\mathrm{a}=3,656 \mathrm{~A}$.

Table 1. The dimensions of carbide grains in the carbidostal are TiC-45\% I2XI8HIOT

\begin{tabular}{|c|c|c|c|c|c|c|c|}
\hline \multirow{3}{*}{ Alloy State } & \multirow{6}{*}{ Sample area } & \multicolumn{3}{|c|}{ Grain distribution TiC by size \% } & Average \\
\cline { 3 - 8 } & & $\begin{array}{c}\text { Under } \\
2 \mu\end{array}$ & $\begin{array}{c}2-3 \\
\mu \mathrm{m}\end{array}$ & $\begin{array}{c}3-4 \\
\mu \mathrm{m}\end{array}$ & $\begin{array}{c}4-5 \\
\mu \mathrm{m}\end{array}$ & $\begin{array}{c}5-7,5 \\
\mu \mathrm{m}\end{array}$ & $\begin{array}{c}\text { grain size, } \\
\mu \mathrm{m}\end{array}$ \\
\hline \multirow{3}{*}{ After impregnation } & Top & 63,0 & 27,3 & 7,6 & 2,0 & no & 3,10 \\
\cline { 2 - 8 } & Middle & 71,5 & 25,6 & 2,8 & 1 & no & 2,95 \\
\cline { 2 - 8 } & Bottom & 78,5 & 18,7 & 2,0 & 1 & no & 2,82 \\
\hline \multirow{3}{*}{ After annealing } & Top & 46,9 & 31,2 & 17,4 & 0,7 & 0,34 & 3,28 \\
\cline { 2 - 8 } & Middle & 57,5 & 26,0 & 11,8 & 4,0 & no & 3,25 \\
\cline { 2 - 8 } & Bottom & 72,8 & 22,3 & 3,2 & 0,7 & 0,20 & 2,87 \\
\hline \multirow{3}{*}{ After quenching } & Top & 46,6 & 45,1 & 7,8 & 0,4 & no & 3,27 \\
\cline { 2 - 8 } & Middle & 51,2 & 39,7 & 8,4 & 0,7 & no & 3,23 \\
\cline { 2 - 8 } & Bottom & 49,8 & 47,4 & 8,6 & 0,2 & no & 3,46 \\
\hline
\end{tabular}

Thus, the hourly holding at the quenching temperature allows the required amount of titanium carbides to be dissolved in the austenite, and subsequent cooling at a high rate helps to fix a sufficiently large amount of the carbide phase in the solid solution, which provides the necessary austenitic structure to the steel matrix.

The samples were quenched from the heating temperature into oil. No leash, warps and changes in sample sizes were detected during the hardening process.

Table 2. The characteristic of the steel binder is carbidostal TiC-45\% I2XI8HIOT

\begin{tabular}{|c|c|c|c|c|c|c|}
\hline \multirow[b]{2}{*}{ Alloy State } & \multirow{2}{*}{$\begin{array}{l}\text { Sample } \\
\text { area }\end{array}$} & \multicolumn{2}{|c|}{ Content, vol.\% } & \multirow{2}{*}{$\begin{array}{l}\text { Average } \\
\text { size } \\
\text { steel } \\
\text { interlayer, } \\
\mu \mathrm{m}\end{array}$} & \multirow{2}{*}{$\begin{array}{c}\text { Length of } \\
\text { contact line } \mathrm{TiC} \\
\text { - bundle, } \\
\mathrm{mm}^{-1}\end{array}$} & \multirow[b]{2}{*}{$\begin{array}{c}\text { Steel matrix } \\
\text { microhardness, } \\
\mathrm{kgf} / \mathrm{mm} 2\end{array}$} \\
\hline & & $\mathrm{TiC}$ & $\begin{array}{c}\text { Steel } \\
\text { bundle }\end{array}$ & & & \\
\hline \multirow{3}{*}{$\begin{array}{c}\text { After } \\
\text { impregnation }\end{array}$} & Top & 32,5 & 63,5 & 2,80 & 30,9 & $400-550$ \\
\hline & Middle & 31,7 & 68,3 & 2,50 & 29,6 & $400-550$ \\
\hline & Bottom & 40,4 & 59,6 & 2,20 & 31,5 & $400-550$ \\
\hline \multirow{3}{*}{$\begin{array}{c}\text { After } \\
\text { annealing }\end{array}$} & Top & 36,6 & 61,2 & 3,05 & 24,4 & $360-380$ \\
\hline & Middle & 39,6 & 60,4 & 3,00 & 26,4 & $360-380$ \\
\hline & Bottom & 38,9 & 61,2 & 2,89 & 28,2 & $360-380$ \\
\hline \multirow{3}{*}{$\begin{array}{c}\text { After } \\
\text { hardening and } \\
\text { vacation }\end{array}$} & Top & 37,9 & 63,1 & 2,36 & 25,9 & $650-750$ \\
\hline & Middle & 40,6 & 59,4 & 2,46 & 26,8 & $650-750$ \\
\hline & Bottom & 40,4 & 59,6 & 2,41 & 30,9 & $650-750$ \\
\hline
\end{tabular}

The conversion of $\alpha \rightarrow \gamma$ during hardening of the carbidostal TiC - I2XI8HI0T is explained by the dissolution of titanium carbides in austenite during the heating and holding of the alloy. As a result of rapid cooling, carbon and titanium remain in the solid solution. This is indirectly confirmed by the increase in the microhardness of the metal matrix (Table 2) as well as the total 
hardness of the carbidostal. As shown in Tables 1, 2 and Figure 2, the dimensions of carbide grains and steel bundle change little after quenching.

The microstructure of the carbidostal after quenching on untwisted samples also differs little from the starting ones. After etching the slips, you can see the areas sharply delineated by concentration lines (Figure 2). In addition, significant amounts of fine carbides are observed to precipitate.

To relieve stress, the samples after quenching were tempered at $800 \mathrm{~K}$, held at this temperature for 1 - 2 hours and cooled in oil.

Table 3 shows the hardness of the carbidostal after sintering and heat treatment.

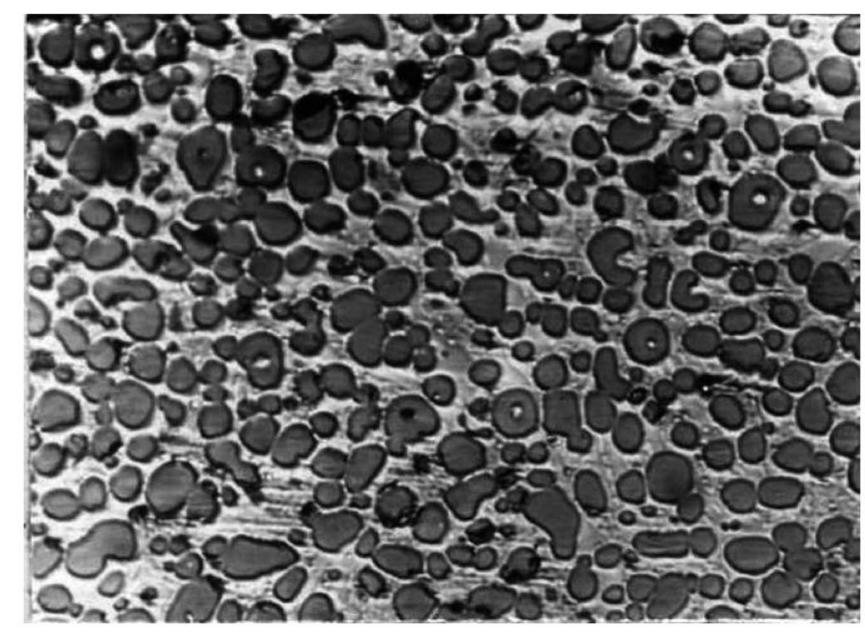

a

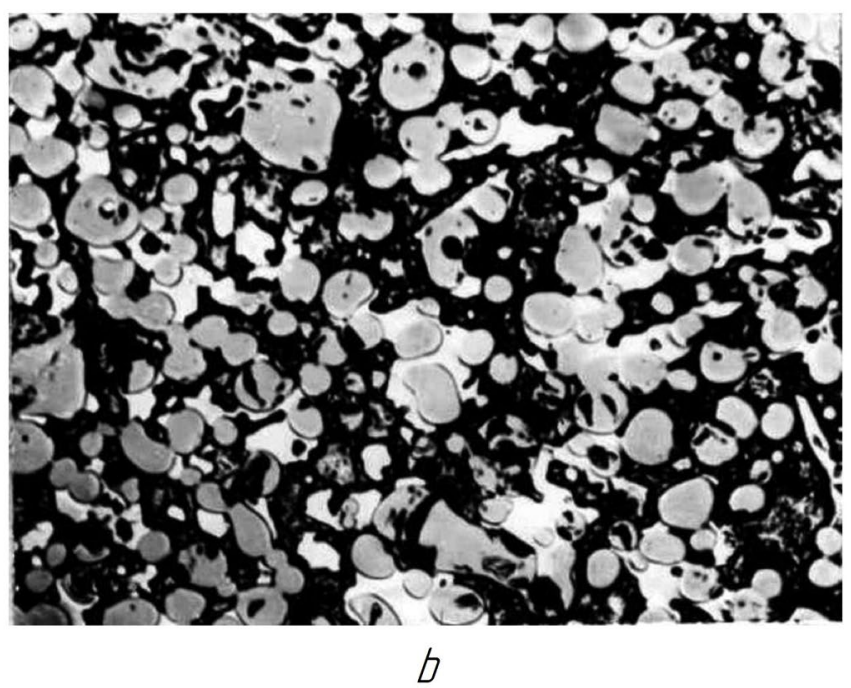

Fig. 2. The microstructure of the carbidostal TiC-I2XI8H10T after quenching: $a$ - untwisted samples, $x 800 ; b-$ samples etched, $x 800$

Based on the results of the study, a technology for producing carbidostal TiC - I2XI8HI0T by impregnation of a green carbide framework $[3,4]$ was developed. 
Table 3. Carbidostal hardness I2XI8HIOT

\begin{tabular}{|c|c|c|c|c|c|}
\hline \multicolumn{2}{|c|}{$\begin{array}{c}\text { Composition, } \\
\text { vol.\% }\end{array}$} & \multicolumn{4}{|c|}{ HRC hardness after } \\
\hline TiC & Steel & Impregnations & Annealing & Trainings & Holidays \\
\hline 55 & 45 & $83,7 \pm 0,8$ & $82,4 \pm 0,8$ & $85,28 \pm 0,16$ & $85,02 \pm 0,18$ \\
\hline 45 & 55 & $81,71 \pm 0,72$ & $80,7 \pm 0,7$ & $84,28 \pm 0,5$ & $83,82 \pm 0,38$ \\
\hline
\end{tabular}

\section{Conclusions}

Thus, quenching and low tempering of the carbidostal TiC - I2XI8HI0T provide an austenitic structure to the metal matrix and increase the hardness of the carbidostal.

\section{References}

[1] S.S. Kiparisov, V.K. Narva, L.I. Dalyaeva, News universities. Non-ferrous metallurgy 2, 136140 (1976)

[2] S.S. Kiparisov, I.V. Paisov, V.K. Narva, Powder metallurgy 9, 10-13 (1969)

[3] Yu.G. Gurevich, V.B. Akimenko, N.R. Frage, L.M. Savinykh, Steel 10, 77-78 (1981)

[4] Yu.G. Gurevich, L.M. Savinykh, Powder Metallurgy, 13-14 (1984) 